\title{
El patrimonio musical y las nuevas tecnologías de la información en la Biblioteca Nacional de España (BNE)
}

\author{
Musical Heritage and New Information Technologies \\ in Biblioteca Nacional de España (BNE)
}

José Carlos Gosálvez Lara

Biblioteca Nacional de España josecarlosgosalvezlara@gmail.com

\section{RESUMEN}

Las innovaciones tecnológicas de los últimos años han revolucionado los procedimientos de trabajo en las bibliotecas, redefiniendo la figura del bibliotecario y transformando el mundo de la investigación, aunque el creciente volumen de información requiere ser analizado con aún mayor espíritu crítico. El presente artículo menciona algunos de estos cambios en las colecciones musicales de la BNE y su plasmación en recientes proyectos tecnológicos.

Palabras clave: Archivado Web, Biblioteca Nacional de España, Biblioteca Digital Hispánica, Depósito legal, Digitalización, Nuevas tecnologías, Patrimonio musical.

\section{Abstract}

The technological innovations in the past years have revolutionized the library working procedures, redefining the librarian's figure and changing the research world, although the increasing amount of information requires to be analysed with higher critical thinking. The present paper refers to some of these changes in the BNE musical collections and Its implementation in recent technological projects.

Key words: Web Archiving, National Library of Spain, Hispanic Digital Library, Legal Deposit, Digitalization, New Technologies, Musical Heritage.

Gosálvez Lara, J. C. (2016). El patrimonio musical y las nuevas tecnologías de la información en la Biblioteca Nacional de España (BNE). Cuadernos de Investigación Musical, 1, 1-11. 


\section{INTRODUCCIÓN}

Cualquier texto que aborde en nuestros días las novedades tecnológicas en el mundo de las bibliotecas está condenado a un envejecimiento inmediato, aún más si se refiere a una especialidad tan amplia, compleja y dinámica como es la música. A la vista de la rapidez de los cambios, apenas somos capaces de imaginar qué será del mundo bibliotecario de aquí a unos pocos años, por lo que no tenemos más remedio que limitarnos a hacer de cronistas del presente y del pasado inmediato. Este artículo no pretende otra cosa que dejar constancia de algunas iniciativas tecnológicas recientemente desarrolladas en la primera biblioteca del país, además de expresar opiniones personales que pueden ser compartidas o no, y que han tomado forma durante los últimos años de mi experiencia en la gestión de colecciones musicales de la Biblioteca Nacional de España.

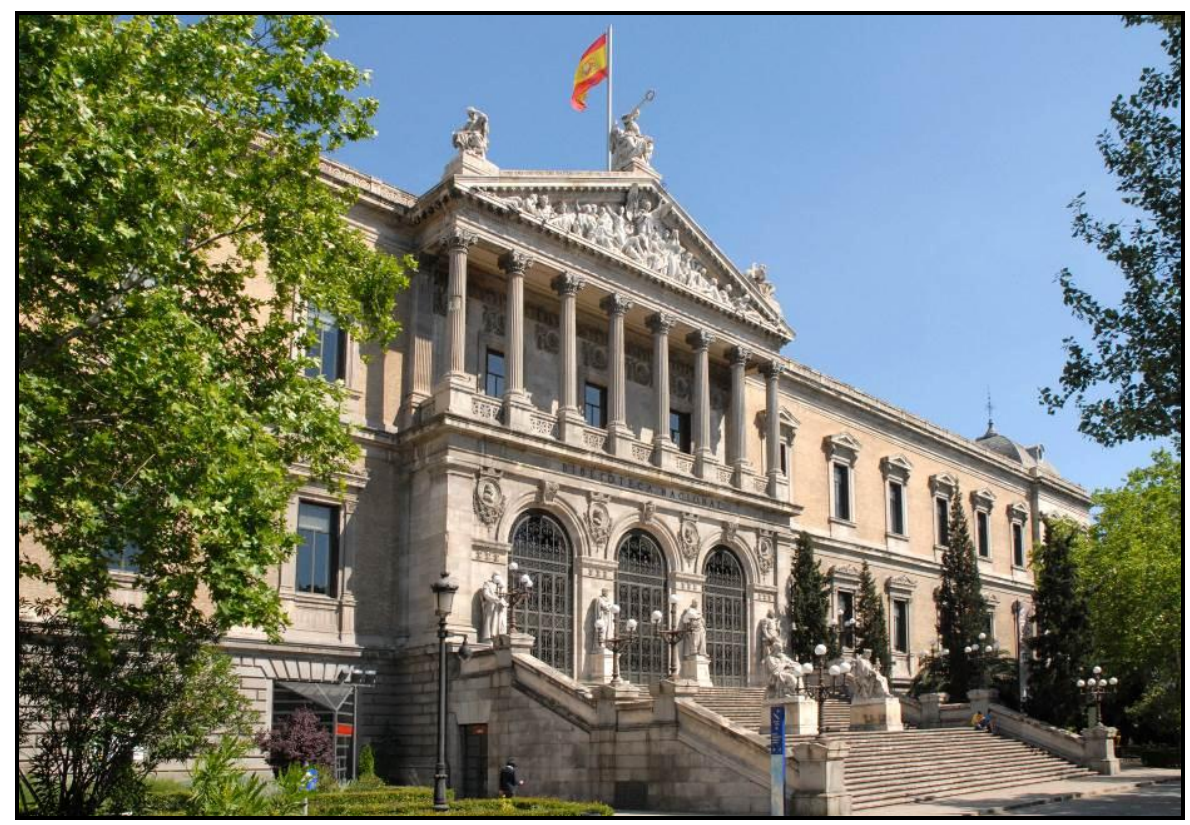

Fig. 1. Sede de la Biblioteca Nacional de España (BNE) en Madrid, fachada principal

\section{UN RETO BIBLIOTECARIO}

El concepto de patrimonio está vinculado a la idea de la transmisión. Define el conjunto de bienes que hemos heredado, que incrementamos, preservamos y tenemos la responsabilidad de transmitir a las próximas generaciones. El patrimonio es la plasmación de nuestra memoria y de nuestra cultura colectiva y las bibliotecas patrimoniales son aquellas que, como la BNE, tienen como principal misión ser eslabón en esa cadena que enlaza el pasado con el futuro. Estos bienes culturales que custodiamos estuvieron hasta hace muy poco tiempo contenidos únicamente en soportes físicos (manuscritos, libros impresos, partituras, publicaciones periódicas en papel, discos de pizarra o de vinilo, etc.), que nos llegaban por distintas vías, fundamentalmente por compras, donaciones y, sobre todo, con el cumplimiento de la legislación de depósito legal, que en España tiene sus más 


\section{EL PATRIMONIO MUSICAL Y LAS NUEVAS TECNOLOGÍAS DE LA INFORMACIÓN EN LA Biblioteca NaCional de EsPaña (BNE)}

antiguos precedentes en los privilegios reales concedidos al Monasterio del Escorial a principios del siglo XVII. Llamamos depósito legal a la normativa que obliga a los impresores, editores y fabricantes de productos culturales a entregar gratuitamente al Estado, por medio de las bibliotecas patrimoniales, una serie de ejemplares de todo lo que publican, con el fin de que pasen a integrar nuestro patrimonio bibliográfico y documental colectivo.

La Real Biblioteca Pública (1711-1836), embrión de la actual Biblioteca Nacional de España, nació hace algo más de tres siglos precisamente con esa función patrimonial; desde entonces, la sucesivas leyes de imprenta, de propiedad intelectual y de depósito legal (la última, de 2011), han generado la afluencia de millones de documentos a la BNE. En consecuencia, su historia estuvo hasta hace muy poco tiempo indisolublemente ligada a la evolución de los soportes físicos, una circunstancia que condicionaba el trabajo de los bibliotecarios (por ejemplo, la catalogación se orientaba más a la descripción externa de los documentos que a la descripción de sus contenidos), pero ahora todo se ha transformado radicalmente con la innovación tecnológica y las nuevas formas de difusión de la cultura a través de cauces intangibles, carentes de soporte físico: publicaciones en línea en forma de blogs, libros electrónicos, prensa digital y revistas electrónicas, páginas Web, bibliotecas virtuales, redes sociales, podcasts de radio y televisión, distribuidores de música y vídeo en línea en sus diferentes modalidades, etc. Además, en los últimos años se ha avanzado extraordinariamente en en el perfeccionamiento del "atril electrónico", para la práctica musical, y en sistemas de digitalización de textos musicales con reconocimiento de signos y conversión en sonido.

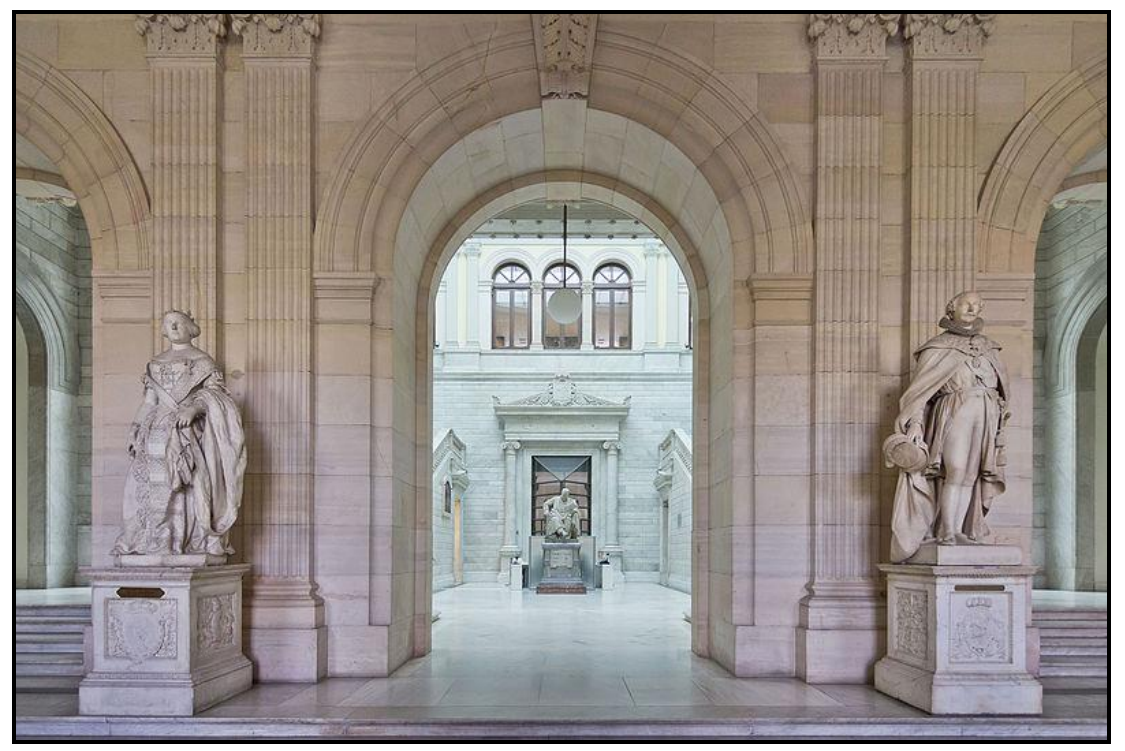

Fig. 2. Biblioteca Nacional de España (BNE), interior

$\mathrm{Al}$ comenzar esta formidable revolución cultural a la que asistimos desde hace apenas una década (hay que recordar que las primeras directrices sobre preservación del 
JosÉ CARLOS GOSÁLVEZ LARA

patrimonio digital de la UNESCO se remontan tan solo a 2003), muchos bibliotecarios que trabajamos en bibliotecas históricas tuvimos la impresión de que nuestro papel de intermediarios entre la información y sus demandantes se había acabado, ya que cualquiera puede acceder a ella de forma directa. Muchos pensábamos que nuestra profesión desaparecería arrollada por la historia, igual que desaparecieron en su día los oficios de aguador o arriero.¿De qué sirven ya nuestras descripciones bibliográficas detalladas, que tratan de reflejar la presencia y contenido de los documentos, si todo el mundo puede acudir directamente a los textos y las imágenes utilizando simplemente los buscadores de Internet? Pero afortunadamente para nosotros, y supongo que también para muchos de nuestros usuarios, el paso del tiempo parece no haber dado la razón a los agoreros y, aunque es verdad que las bibliotecas han perdido muchísimo peso como centros emisores de información, también es cierto que la gigantesca proliferación de imágenes y datos que hace diez años parecía amenazar nuestra profesión, al crecer exponencialmente, se ha diversificado aún más y se ha hecho cada vez más incontrolable; la necesidad de poner orden en todo ese caos es ahora la clave del futuro de nuestra profesión de bibliotecarios y documentalistas.

\section{COGIENDO AGUA CON UN COLADOR}

Disponer de un mar de información no controlada equivale a veces a no tener nada, por lo que es necesario someterla a un procesamiento bien organizado, y en eso nosotros tenemos experiencia. Con la primera gran revolución bibliotecaria que supuso la informatización de los catálogos a partir de los años ochenta del siglo pasado, tuvimos que adaptar profundamente nuestra normativa de descripción bibliográfica, desarrollamos el formato MARC 21 y las normas internacionales de descripción y catalogación que permiten la tranferencia de información, y que fueron adoptadas en todo el mundo; toda esta normativa internacional fue concebida con una gran visión de futuro y enorme versatilidad, de forma que ahora, ante esta nueva revolución tecnológica, están demostrando buena capacidad de adaptación a un entorno diferente. Los criterios de catalogación que empleamos actualmente se orientan a la elaboración de metadatos, y a la búsqueda y recuperación de información, mucho más que, como hacíamos antes, a la mera descripción de los documentos.

La irrupción de Internet y de la tecnología digital es la gran revolución de nuestros días, que ha hecho que el propio concepto de documento se haya difuminado por completo; ahora la cultura puede transmitirse sin soporte material que la sustente y las bibliotecas patrimoniales, que orientaban sus procesos técnicos y su trabajo a la gestión del patrimonio tradicional, se ven ahora ante una tarea nueva, semejante a la de coger agua con un colador: deben recolectar y catalogar lo intangible. Por supuesto, el trabajo bibliotecario tradicional no ha sido sustituido totalmente y sigue existiendo (cada año ingresan en el Departamento de Música y Audiovisuales de BNE una media de 22.000 nuevos documentos en forma de partituras, libros sobre música, discos de vinilo, DVD y CDA), pero ahora ese patrimonio convive con la cultura virtual que gana terreno a una velocidad vertiginosa. Como primer centro patrimonial de España, la BNE se ha planteado también 


\section{EL PATRIMONIO MUSICAL Y LAS NUEVAS TECNOLOGÍAS DE LA INFORMACIÓN EN LA Biblioteca NaCional de EsPaña (BNE)}

la necesidad de preservar ese otro tipo de patrimonio y participamos muy activamente en la redacción del Real Decreto 635 publicado en julio de 2015, que regula el depósito legal de las publicaciones en línea, lo que también denominamos "recolección Web” o "depósito legal electrónico"; esta normativa rige por primera vez esa tarea en nuestro país y ha entrado en vigor hace apenas un año. La BNE, en colaboración con las distintas bibliotecas centrales de las Comunidades Autónomas, abandona desde ahora la actitud pasiva en la recepción del depósito legal, deja de estar tras el mostrador esperando que llegue, y se lanza a una recolección activa, rastreando mediante robots todo el contenido de la Web a la búsqueda de cualquier información relacionada con la cultura española que merezca ser preservada. Los softwares de recuperación permitirán acceder a las páginas Web cuando estas ya no existan en la red o cuando sus contenidos hayan desaparecido o hayan sido modificados.

Es un trabajo inmenso, que supone capturar millones de URLS en continuas recolecciones, haciendo fotos fijas de la Web que superen su carácter efímero y que conviertan sus contenidos en algo permanente, procesable y almacenable en gigantescos servidores. La Biblioteca ya estaba muy preparada para ello y a comienzos de 2016, recién iniciada la aplicación del Real Decreto, ya se habían ocupado unos 111 teras de capacidad de almacenamiento, con unos cinco millones de sitios Web guardados en archivos comprimidos. En esa tarea la Biblioteca contó con la colaboración de la organización Internet Archive, que hizo entre 2009 y 2013 ocho rastreos masivos del dominio ".es" (aunque la recolección Web española alcanza también a cualquier otro dominio que nos interese, como .cat, .com, .edu, .gob, .org, .net.); también contamos con el apoyo técnico y financiero de la entidad pública RED.ES, dependiente del Ministerio de Industria, Energía y Turismo, que actualmente apoya los planes de digitalización de BNE y ha hecho una importante inversión en la puesta en marcha de este proyecto; a nivel técnico bibliotecario, hay que agradecer también la ayuda prestada por la Bibliothèque Nationale de France $(\mathrm{BNF})$, cuya experiencia en la recolección Web es anterior a la nuestra, pues se remonta a 2005, y que nos ha cedido aplicaciones que permiten el procesamiento de toda la información capturada. Con las herramientas adquiridas por BNE se hizo en 2015 una primera prueba de 14.000 páginas Web (de ellas cerca de mil de nuestra especialidad musical) y, posteriormente, se programaron para comienzos de 2016 los primeros rastreos masivos contando exclusivamente con medios propios. En nuestro Departamento designamos a dos personas para coordinar la recolección de páginas Web de música y audiovisuales y también para ocuparse del control de calidad. Debido a la envergadura del proyecto de la Web española, la BNE fue invitada en 2014 a formar parte del Consejo Directivo del Consorcio Internacional para la Preservación de Internet (International Internet Preservation Consortium -IIPC-), una organización que aglutina las iniciativas más importantes a nivel mundial en el campo del archivado web. 
JOSÉ CARLOS GOSÁLVEZ LARA

\section{HERRAMIENTAS PARA CAMBIAR EL MUNDO DE LA INVESTIGACIÓN}

Sin duda uno de los rasgos más característico de las nuevas tecnologías es su rápida obsolescencia. Cada día nacen y desaparecen miles de páginas Web, cada día surgen nuevos productos tecnológicos que son rápidamente sustituidos. La velocidad con la que se suceden los cambios marca un ritmo frenético en los centros donde gestionamos un patrimonio cultural que surge, se transforma y se esfuma a tal velocidad que nos obliga a mantenernos siempre alerta para evitar pérdidas catastróficas. Muchas bibliotecas se plantean la conveniencia de no invertir en la adquisición y catalogación de productos demasiado efímeros y minoritarios, que previsiblemente podrían aparecer en otros soportes futuros, ya que el coste medio del proceso técnico en BNE en 2015 era muy elevado, entre 8 y 12 euros por cada documento catalogado. No obstante, a pesar de sufrir desde hace años, como otros muchos organismos públicos, continuos recortes de plantilla y presupuesto, la Biblioteca no ahorra esfuerzos y se impone la tarea de procesarlo prácticamente todo.

Las novedades tecnológicas generan fenómenos de creación cultural hasta ahora desconocidos y que rompen los moldes anteriores, causando una gigantesca transformación de las formas de producción, acceso y difusión de la cultura. El impacto inmediato en las bibliotecas y en la investigación de nuestra especialidad musical se traduce en la existencia de enormes catálogos colectivos de fuentes, como RISM, que desde mayo de 2015 reúne y ofrece gratuitamente sus dos series más importantes, y que desde 2016 incorpora el catálogo de manuscritos musicales de BNE; también en la enorme disponibilidad de música grabada de recursos como Spotify, en el avance hasta hace pocos años inimaginable de las grandes bibliotecas virtuales de música, como el proyecto IMSLP Petrucci (activo desde 2008), con cientos de miles de partituras accesibles en formato digital; también en la posibilidad de utilizar buscadores que trabajan simultáneamente con millones de registros bibliográficos existentes en bibliotecas de todo el mundo, como Worldcat, etc. En la investigación musical todo esto supone un cambio histórico para el que tenemos que adaptarnos casi cada día y que ha abierto un círculo positivo de avances encadenados y consecutivos. Una de las primeras consecuencias es que los nuevos recursos tecnológicos han propiciado en casi todas las grandes bibliotecas un control mucho mayor de las colecciones: en el Departamento de Música y Audiovisuales de la BNE, donde conservamos más de trescientas mil partituras, hoy queda menos de un 3\% de la colección histórica pendiente de catalogar. La necesidad de compartir información ha hecho posible la creación de redes de trabajo cooperativo que facilitan nuestra tarea, pero también hemos desarrollado proyectos de digitalización masiva de música que posibilitan un cómodo acceso desde nuestras casas a un número asombroso de documentos, lo que habría hecho las delicias de grandes investigadores del pasado como Francisco Barbieri, Felipe Pedrell, Rafael Mitjana, Higini Anglés, Robert Stevenson o José Subirá, que trabajaron artesanalmente y de forma heroica a la búsqueda de fuentes musicales, visitando cada archivo y cada biblioteca, en un momento en que apenas existían catálogos. 


\section{EL PATRIMONIO MUSICAL Y LAS NUEVAS TECNOLOGÍAS DE LA INFORMACIÓN \\ EN LA BIBLIOTECA NACIONAL DE ESPAÑA (BNE)}

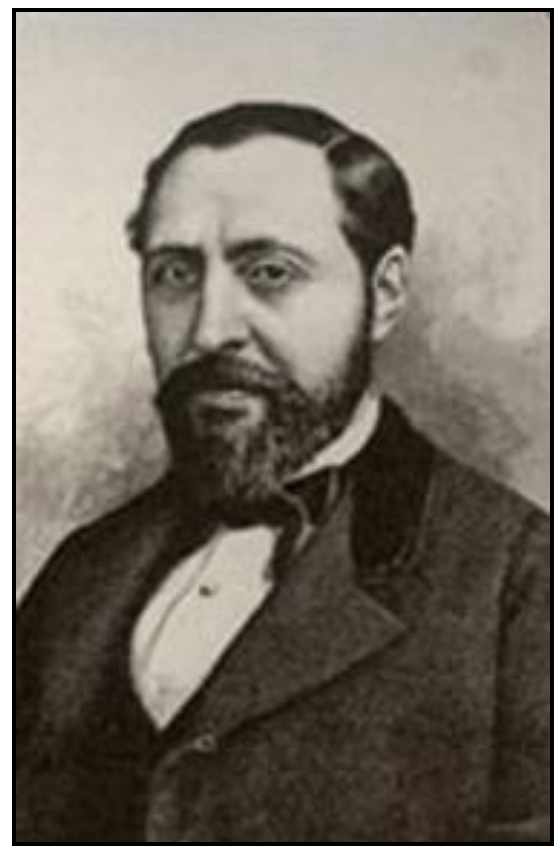

Fig. 3. Francico Asenjo Barbieri, cuyo nombre ha sido asignado a la sala de lectura del departamento de Música y Audiovisuales (BNE)

Solamente en el Departamento de Música de la BNE hemos digitalizado en los últimos cuatro años alrededor de 50.000 obras que ya están disponibles en la Biblioteca Digital Hispánica (BDH), mientras que en el Departamento de Publicaciones Periódicas de nuestra Biblioteca ya hay escaneados más de 25 millones de páginas, disponibles en Hemeroteca Digital (HM), con numerosas referencias musicales. En realidad ya no podemos hablar con propiedad de una única BNE, sino de dos, la biblioteca real y la virtual, ambas con sus colecciones, servicios e, incluso, con usuarios diferenciados. En estos últimos años hemos perdido muchos investigadores presenciales, pero a cambio ganamos cientos de miles de usuarios remotos. Por poner un simple ejemplo, en las estadísticas de uso de nuestra biblioteca digital $\mathrm{BDH}$, correspondientes al mes de octubre de 2015, pudimos observar que 14.925 usuarios de todo el mundo se descargaron nuestras partituras y que solo uno de nuestros libros de vihuela del siglo XVI, Los seis libros del Delfín de la música, de Luis de Narváez, fue consultado 193 veces. En dos meses tuvimos 20.046 usuarios que escucharon grabaciones sonoras en nuestra Web y una sola de estas grabaciones de la BDH fue reproducida nada menos que en 2.053 ocasiones (una popular canción brasileña que probablemente circuló por las redes sociales). Evidentemente, muchos de estos usuarios de nuestros fondos musicales, si no la mayoría, no responden ya al perfil del investigador académico, nuestro usuario tradicional, sino más bien al de un músico práctico o al de un público general aficionado, interesado simplemente en ocupar su ocio. 


\section{JOSÉ CARLOS GOSÁLVEZ LARA}

Hasta aquí solamente he hecho hincapié en el impacto de las nuevas tecnologías sobre el incremento de la información disponible, pero su uso tiene también otras vertientes, no menos importantes y no meramente cuantitativas, como la de facilitar un tipo de investigación distinto y hasta ahora insospechado. Eso ocurre, por ejemplo, con las propuestas que ofrece el proyecto DIAMM de digitalización en altísima definición de códices medievales de polifonía, hasta un límite que permite examinar las diferentes capas de escritura de los palimpsestos, o las posibilidades de las nuevas aplicaciones que permiten la transcripción e, incluso, la conversión en sonido de antiguas escrituras musicales, mediante un escaneado con reconocimiento de grafías o de códigos musicales. Dentro de esa línea, en colaboración con la Universidad Autónoma de Barcelona, la BNE ha escaneado en 2016 una selección de 3.645 rollos de pianola, utilizando un procedimiento que convierte directamente en sonido la imagen digital de las perforaciones del papel y cuyos magníficos resultados pueden escucharse en $\mathrm{BDH}$. Otro proyecto reciente de la BNE en relación con las nuevas tecnologías ha sido la aplicación "Cantorales", que dispone de un buscador de melodías gregorianas desarrollado a partir de la codificación de unos diez mil íncipit musicales contenidos en una selección (84 libros) de la colección de 112 libros de coro digitalizados, cuyas imagénes ya están disponibles en nuestra biblioteca virtual $\mathrm{BDH}$.

\section{LA LUZ Y LAS SOMBRAS}

Todo eso, que hace poco parecía ciencia ficción, es hoy una realidad. Los jóvenes investigadores tienen, por tanto, que acompañar su formación musical con un intenso adiestramiento tecnológico que les permita sacar el máximo rendimiento a los nuevos recursos de que disponen; para ello deben desarrollar nuevas habilidades intelectuales muy específicas que a los mayores de cincuenta nos resulta difícil adquirir. Pero todo progreso suele tener una contrapartida, una parte de pérdida, ante la que conviene también estar prevenidos. En este caso la comodidad que propician las nuevas tecnologías pudiera también venir acompañada de una cierta pérdida de la perspicacia necesaria para la búsqueda, debido a una menor necesidad de ejercitar habilidades del ingenio que antes era necesario emplear.

Las investigaciones de grandes musicólogos del pasado eran, sin duda, mucho más penosas e infinitamente más modestas, en cuanto al volumen de información obtenida, que la que cualquiera de nosotros puede hacer hoy con un simple clic de ordenador, pero hay que recordar que el valor cualitativo no es siempre directamente proporcional al cuantitativo. Al facilitarnos la vida, los nuevos recursos no deberían hacernos más perezosos ni menos ingeniosos y analíticos al procesar la información; también es importante tener en cuenta que los diseños de las aplicaciones determinan las formas de uso y, por tanto, pueden convertirse en condicionantes insalvables que nos ponen orejeras de las que ni siquiera somos conscientes. 


\section{EL PATRIMONIO MUSICAL Y LAS NUEVAS TECNOLOGÍAS DE LA INFORMACIÓN EN LA BIBlioteca NaCional de EsPaÑa (BNE)}

De guardar celosamente los fondos, describirlos primorosamente y protegerlos de la mirada de los investigadores (según mis noticias, en algún archivo eclesiástico todavía sigue haciéndose), los responsables de colecciones históricas hemos pasado a ofrecerlos de manera gratuita y masiva a través de las bibliotecas digitales disponibles en la red. Aunque participo mucho más de los nuevos criterios porque, en definitiva, considero que los bibliotecarios y archiveros somos ante todo servidores de la investigación y de la práctica musical, creo que ahora también corremos el riesgo de perder algo importante por el camino. Precisamente en este momento, en que el acceso a una enorme cantidad de datos está al alcance de cualquiera, es cuando debemos incidir más en la formación de un conocimiento profundo sobre la historia de la música y sobre sus fuentes, y en reforzar un espíritu muy crítico que sea capaz de seleccionar, discernir y analizar lo que todos tenemos ante los ojos. Pero esa tarea es cada vez más difícil, precisamente porque los árboles no nos dejan ver el bosque y porque, según mi opinión, desgraciadamente los sistemas educativos no se dirigen precisamente a fomentar el espíritu crítico que ahora nos hace tanta falta.

Otro riesgo, asociado a la fascinación que nos producen los logros espectaculares de las nuevas tecnologías, es una inevitable tendencia a mitificarlas, a confundir los medios, la herramienta tecnológica, con el fin. A lo largo de los años hemos podido comprobar en nuestro trabajo en las bibliotecas musicales que esa fascinación crea a veces, entre los usuarios menos perspicaces, una falsa percepción de exhaustividad en el control de las colecciones. A más de un investigador, la consulta de servicios en línea le proporciona una impresión de seguridad y de control que frecuentemente no se corresponde con la realidad, ya que no conozco ninguna gran biblioteca controlada completamente en un catalogo automatizado, y de hecho es que no debería existir a menos que estuviera muerta. Además, las bibliotecas digitales, siendo a veces inmensas, nunca suponen más que una pequeña proporción de todo lo que hemos conservado en papel o en soportes de sonido analógicos. Por eso siempre aconsejamos a nuestros usuarios que, además de consultar los catálogos en línea y las colecciones digitalizadas, venzan la tentación de limitar sus investigaciones a lo que puedan obtener fácilmente desde sus domicilios; les sugerimos que visiten las bibliotecas, los archivos y museos, preguntando a sus gestores, que son quienes mejor conocen las colecciones catalogadas y sin catalogar. Si no procedemos así, podría darse la paradoja de que en la época de mayor control de la información, todas las consultas se concentren en los materiales cómodamente accesibles, permaneciendo al margen de la investigación todo aquello no disponible en los nuevos recursos tecnológicos: cuanto más potente y concentrado es un foco de luz, más densas son las sombras que proyecta a su alrededor.

Una última observación sobre el peligro de basar la investigación exclusivamente en documentos digitalizados se refiere a su propia naturaleza inmaterial. De tal forma incide la digitalización en la preeminencia de los contenidos, que estos aparecen a menudo disociados de sus continentes físicos originales; la sustancia intelectual se desprende de los soportes que la sustentan, invitándonos a no tener en cuenta el contexto cultural y sociológico en el que fueron producidos. Las colecciones de todas las grandes bibliotecas van fundiéndose en el magma de la información y, consecuentemente, pierden 


\section{JOSÉ CARLOS GOSÁLVEZ LARA}

paulatinamente su individualidad; cada vez son más los trabajos sobre fuentes históricas realizados por investigadores que nunca pisaron los archivos y bibliotecas donde se conservan. Comprobamos a diario como un manuscrito con música de Sebastián Durón, una determinada obra de Tomás Luis de Victoria, una armonización de una canción o una grabación histórica de fonógrafo, por poner solo unos pocos ejemplos, corren por la red sin que parezca importante conocer a qué colección pertenecen, dónde está la fuente original, quién fue el propietario del ejemplar del que se ha extraído, qué recorrido ha seguido el documento original, quién hizo el arreglo, quién fue el intérprete, quien hizo la grabación o la copia, así como cualquier otro dato relacionado con su plasmación material. Al fijarnos solamente en el contenido perdemos, sin darnos mucha cuenta de ello, una parte de información relevante en la investigación y que es fundamental para comprender la obra, su significado y todo el contexto histórico y sociológico asociado al documento que la sustenta.

Parece que las bibliotecas históricas siempre tendrán una responsabilidad de custodia de los ejemplares físicos, pero esto no debería convertirlas en museos cerrados. La Biblioteca Nacional de España tiene las cosas muy claras en este punto, pero no podría asegurar que para otros centros, especialmente los de gestión privada, no vaya haciéndose hueco cada vez mayor la idea del expurgo, justificado por la preservación de los contenidos mediante la digitalización: en más de uno se discute la conveniencia de conservar los objetos físicos, con todos los costes que supone y las necesidades de ocupar grandes espacios de depósito, una vez que los contenidos de estos ya hayan sido preservados por la digitalización.Tampoco es una cuestión menor, aunque ahora no nos detengamos en ello, el problema que plantea la preservación de los propios archivos digitales, que obliga a una continua actualización y a un proceso de constante migración de los archivos a formatos actualizados, para evitar el riesgo de pérdida.

En estos últimos años vivimos un momento de transición en el mundo de las bibliotecas que recuerda mucho al que ya vivimos hace algo más de treinta años, en la época de la reconversión de los antiguos ficheros de cartulina en los nuevos catálogos automatizados. La moda bibliotecaria de entonces era la reconversión y la automatización, la de ahora es la digitalización y las nuevas tecnologías de la información. Como entonces, hoy vivimos un momento de agitación y también de esperanza. Estamos en la nueva época de la digitalización masiva de las grandes bibliotecas históricas, de la recolección de la Web española a través del depósito legal electrónico, de la adaptación al entorno digital y de la "Web semántica", que transforman radicalmente nuestra profesión en todos sus aspectos. Como entonces, tenemos que adaptarnos a los nuevos tiempos, y un centro como la BNE está en el ojo del huracán de ese mundo cambiante.

En mi opinión, el estudio de la música histórica adquiere todo su sentido si tenemos capacidad de disfrutar de ella, así que el esfuerzo de acumular información solo se justifica si sabemos procesarla para lograr una satisfacción intelectual. Aunque surjan nuevos recursos y procedimientos, aunque todo se mueva a nuestro alrededor, hay algo que siempre deberá permanecer en el estudio de nuestro pasado musical: la humana curiosidad que mueve toda investigación. Desde una tesis doctoral hasta el más modesto trabajo de 
EL PATRIMONIO MUSICAL Y LAS NUEVAS TECNOLOGÍAS DE LA INFORMACIÓN

EN LA BIBLIOTECA NACIONAL DE EsPaÑa (BNE)

curso deberían partir siempre de esa chispa que nos hace buscar con empeño la música que nos gustaría escuchar o interpretar, y de la fuerza que nos impulsa a conocer mejor a los artistas del pasado que siguen conmoviéndonos con sus obras.

Fecha de recepción: 10/11/2016

Fecha de aceptación: 13/12/2016 